\title{
Immunohistochemical localization of androgen receptors in the urogenital tracts of human embryos
}

\author{
Yasmin Sajjad, Siobhan Quenby, Paul Nickson, D Iwan Lewis-Jones and Gill Vince ${ }^{1}$ \\ Department of Obstetrics and Gynaecology, First Floor, Liverpool Women's Hospital, Crown Street, \\ Liverpool L8 7SS, UK and ${ }^{1}$ Department of Immunology, University of Liverpool, Liverpool L69 3BX, UK
}

Correspondence should be addressed to S Quenby; Email: squenby@liv.ac.uk

\begin{abstract}
The aim of this study was to investigate androgen receptor (AR) expression in the developing human urogenital tract. The distribution of AR was examined in paraffin-embedded tissue sections of the lower urogenital tract using 55 human embryos of 8-12 weeks of gestation. Immunohistochemistry was performed for AR detection and gender was determined by polymerized chain reaction. There were no differences in the distribution of AR in male and female embryos at any stage of gestation. AR was present only in the mesenchymal tissues of the urogenital sinus at 8 weeks whilst the epithelium was negative, but after 9 weeks the epithelium also showed progressively more positive staining. In the phallus, AR staining was prominent. There was far less staining in the epithelium of the urethral groove from 8 to 10 weeks, whilst the mesenchyme of the urethral folds showed positive staining. At 11 and 12 weeks, both the urethral groove and folds showed uniform staining. The genital tubercle, genital swelling and bulbourethral gland precusors were also positively stained, although paramesonephric ducts were negative. Staining was observed in the mesonephric duct from 9 weeks. There was an absence of staining in the rectum at all stages of gestation. The expression of AR in an epithelium may be dependent upon the mesenchyme. Mesenchymal-epithelial interactions played an important role in development, as has been described in experimental animals. AR expression could play a part in the growth of the genital organs.

Reproduction (2004) 128 331-339
\end{abstract}

\section{Introduction}

Androgens act by binding to a specific protein target, the androgen receptor (AR), in androgen-responsive cells (Loy \& Yong 2001). The AR belongs to the large family of steroid hormone receptors (Quigley et al. 1995). Ligand binding is essential for the activation of the receptor which then binds to specific targets on DNA resulting in modulation of the level of gene expression (Rundlett et al. 1990). These receptors are present in both the epithelium and stroma of juvenile and adult reproductive organs (Stumpf \& Sar 1976, Takeda et al. 1990).

In the embryo, the development of the sex-specific phenotype depends on the presence or absence of androgens during the phase of organogenesis of the genital tract, i.e. genital ducts and external genitalia (Wilson et al. 1981, Winters et al. 1981, Cooke et al. 1991a).

The ducts are derived from two closely related systems - the mesonephric (MD) and paramesonephric ducts (PMD). These two ducts are related to the endodermal urogenital sinus (UGS) and to the external genitalia (Jirásek 1967). The MD in the male give rise to the epididymis, the ductus deferens, seminal vesicles and the ejaculatory ducts (Siiteri \& Wilson 1974, Sadler 1995). In females, the PMD give rise to the Fallopian tubes, the uterus, the cervix and the upper part of the vagina. Feminization of the external genitalia occurs in all cases where androgens are not present at the correct time, or in cases where the target tissues are androgen insensitive (Jirásek 1971).

Androgens, via the $A R$, induce the differentiation of male internal genitalia from the fetal UGS and MD (Wilson et al. 1981, Winters et al. 1981). Sertoli cells of the testes begin to secrete anti-Mullerian hormone or Mullerian inhibiting factor (MIF), which is responsible for regression of the PMD in the male (Josso et al. 1993, Lee \& Donahoe 1993, Drews et al. 2001). Regression begins at 10 weeks (Taguchi et al. 1984). Sertoli cells also stimulate differentiation of the Leydig cells from the testicular interstitial cells (Pellinicmi et al. 1993). Leydig cells secrete testosterone, the main androgen inducing the differentiation of male internal genitalia from the fetal UGS (Jirásek et al. 1968, 1969, Cooke et al. 1991a, Pellinicmi et al. 1993). Differentiation begins at 8 weeks of gestation (Siiteri \& Wilson 1974, Wilson et al. 1981, 
Winters et al. 1981, Cooke et al. 1991b). The differentiation of external genitalia depends upon $5 \alpha$-dihydrotestosterone (DHT), a metabolite of testosterone (Wilson 1993). The conversion of testosterone to DHT is brought about by an enzyme, $5 \alpha$-reductase, produced by the cells of the UGS, genital tubercle and genital swellings at the same time as the testis begins to secrete testosterone (Siiteri \& Wilson 1974, Wilson et al. 1993).

During early development of the male mouse genitalia, the distribution of $A R$ differs from that found in later stages, in that AR expression is initially present only in mesenchymal cells and later also appears in the epithelium (Cooke et al. 1991a). Studies in laboratory animals have shown similar findings where androgens induce epithelial differentiation in the genitalia via action on mesenchymal cells (Shannon \& Cunha 1983, Takeda et al. 1984).

AR-positive cells are found in the mesenchyme of the UGS and MD of the mouse fetus but the epithelium is negative (Stumpf \& Sar 1976, Shannon \& Cunha 1983, Wasner et al. 1983, Cooke et al. 1991a). A similar pattern of AR expression is also seen in the UGS and prostate of the developing rat (Takeda et al. 1984). It has been suggested that, in mice, the mesenchyme may control initial epithelial AR expression (Sagimura et al. 1986) such that the expression of AR activity within the epithelium is determined via inductive interactions with the mesenchyme with which it is associated during development (Cunha et al. 1980).

ARs have previously been found in the human fetal urogential tract in the second trimester (Amuller et al. 1998, Shapiro et al. 2000) and one first trimester specimen (Shapiro et al. 2000). Here, the expression of AR in the human UGS has been examined together with the mesenchymalepithelial interaction in a large series of first trimester human fetal tissues.

\section{Materials and Methods \\ Patient population}

This study was approved by the Liverpool Research Ethics Committee. After giving informed consent, the patients were recruited from the termination clinic. Women selected for this project were those who were having therapeutic termination of pregnancy. As ultrasound scans were not performed prior to the termination, the gestational age of the fetus was calculated by the last menstrual period and the foot length measurements (in $\mathrm{mm}$ ) as has been described in previously published data (Streeter 1920, Kellokumpu-Lehtinen 1984, Munsick 1984). In this paper the gestational age rather than weeks after conception is used to date the specimens.

The procedure of suction and currettage was used for terminations. To prevent the specimen from clotting, phosphate-buffered saline (PBS), containing $100 \mathrm{ml} 2500 \mathrm{IU}$ heparin (CP Pharmaceuticals, Wrexham, Clwyd, UK) was added to the evacuation container before the sample was added. PBS ( $\mathrm{pH}$ 7.6) was used to wash the samples, so that the pelvic parts could be identified easily for assessment. The selected fetal tissues were placed in processing cassettes to hold the tissue specimens during embedding (BDH, Poole, Dorset, UK). Four percent buffered paraformaldehyde $(\mathrm{BDH})$ was used to fix the fetal tissues at $4{ }^{\circ} \mathrm{C}$ for $24 \mathrm{~h}$. Fifty-seven samples of 8-12 weeks of gestational age (6-10 weeks post conception) were collected.

\section{DNA extraction}

In order to determine the sex of the fetal samples used in this study, sex karyotyping was performed on paraffinembedded sections from the 57 fetuses of 8-12 weeks of gestational age. PCR was used to detect the presence of $X$ and $Y$ chromosome material at Amelogenin (AMXYspecific for $X$ chromosome) and SRY (for $Y$ chromosome) loci. DNA was extracted using standard phenol chloroform extraction methods. For each set of reactions, two known male and female samples were used as positive controls.

The primers used were AMXY-1 (TGACCAGCTTGGTTCTAWCCCA), AMXY-2 (CARATGAGRAAACCAGGGTTCCA), SRY forward (dGTCCAGTTGCACTTCGCTGCCG and SRY reverse (dAGGCAACGTCCAGGATAGAGTGAAG) (Invitrogen, Paisley, Strathclyde, UK). PCR was performed and the products run out on an agarose gel $(2 \%)$. Molecular weight standards (pBR 322) were included on each gel to identify the size of the bands obtained. A negative control (water) was also included. The absence of bands in this lane ruled out contamination. The resultant bands were then photographed.

\section{Immunohistochemistry}

After fixation, tissues were processed in a tissue-processing machine (Shandon Scientific, London, UK) and wax blocks were cast. Paraffin sections $(5 \mu \mathrm{m})$ were cut and mounted on microscopic slides, which were coated with 10\% poly-L-lysine (Sigma, Poole, Dorset, UK) for $10 \mathrm{~min}$ prior to use.

The sections were dewaxed in two baths of xylene for $20 \mathrm{~min}$ and then rehydrated in descending grades of ethanol. Antigen retrieval was carried out by the pressure cooker method for $2.5 \mathrm{~min}$ in citric acid buffer at $\mathrm{pH}$ 6.0. To block any endogenous peroxidase activity, the sections were treated with $1 \%$ aqueous hydrogen peroxide (Sigma) in water for $10 \mathrm{~min}$. Prior to staining, these sections were transferred to Tris-buffered saline (TBS, pH 7.4). To determine the optimum dilution for the AR antibody, a series of experiments was performed for the primary antibody, and a dilution of 1 in 50 was selected. The slides were rinsed with distilled water and placed in TBS for $5 \mathrm{~min}$.

Sections were incubated for $30 \mathrm{~min}$ in a humidity chamber using the primary antibody, mouse anti-human androgen receptor antibody (AR 441; Dako, Cambridge- 
shire, UK) diluted 1 in 50 in TBS. Following incubation, the sections were washed three times in two baths of TBS for $5 \mathrm{~min}$ each. Slides were then incubated for $30 \mathrm{~min}$ with secondary rabbit anti-mouse immunoglobulins (Z0259; Dako) at a dilution of 1 in 25 in TBS. After three washes in TBS, the sections were incubated for $30 \mathrm{~min}$ with peroxidase-antiperoxidase mouse monoclonal (P0850; Dako) at a dilution of 1 in 100 in TBS. After further washing in TBS, visualization was carried out using 3,3'-diaminobenzidine tetrahydrochloride (DAB) (Sigma). DAB acts as a chromogen and is responsible for the brown coloration of the ARpositive cells. After checking the staining intensity, the sections were washed in water. The sections were counterstained with Harris haematoxylin (Merck, Poole, Dorset, UK) and dehydrated in ascending grades of ethanol. Xylene was used to clear the slides before being mounted in DPX.

Slides were examined by two independent observers who were unaware of the gestational ages.

\section{Results}

Sex karyotyping was performed on 57 fetuses of 8-12 weeks of gestational age. The sex of 55 fetuses was identified but, in two samples, the DNA failed to amplify (Fig. 1, lanes 15 and 17) so 55 samples were therefore used for this study. A male embryo was characterized by three bands (Fig. 1, lane 1 positive control); the upper band, $\mathrm{X}$ specific, at $270 \mathrm{bp}$, the lower band, $\mathrm{Y}$ specific at $100 \mathrm{bp}$ and the middle band, SRY specific at $210 \mathrm{bp}$. A female embryo was characterized by a single band in the gel of approximately 270 bp (X specific) (Fig. 1, lane 2 positive control). Representative samples are shown in Fig. 1.

Samples from gestational ages of 8-12 weeks were used since the UGS could be identified in fetal tissues at 8 weeks but, after 12 weeks, collection was difficult

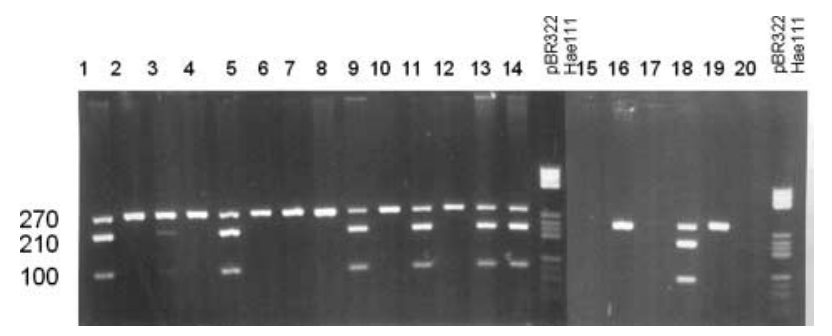

Figure $1 \mathrm{PCR}$-based assay to determine the sex of the sample by amplification of the Amelogenin (AMXY) and SRY loci. The Amelogenin loci produce an X-specific band (270 bp) and a Y-specific band (100 bp). The presence of the SRY gene results in a band of $210 \mathrm{bp}$. Lanes 1 and 18 are the male controls with three bands; an upper band $X$ specific at $270 \mathrm{bp}$, a lower band $\mathrm{Y}$ specific at $100 \mathrm{bp}$ and a middle band SRY specific at $210 \mathrm{bp}$. Male samples are shown by the three bands in lanes 3, 5, 9, 11, 13 and 14. Lanes 2 and 19 are the female controls with a single band at $270 \mathrm{bp}$. Female samples are shown by a single band in lanes 4, 6, 7, 8, 10, 12 and 16. Lane 20 is the water control. In lanes 15 and 17, the Amelogenin and SRY loci DNA failed to amplify, therefore sex could not be identified in that sample. pBR 322 is used as the molecular weight standard. because the samples were easily damaged during the suction termination procedure. The sections were examined and the UGS, phallus, urethral/bulbourethral gland (BUG) precusors and MD and PMD were identified in both male and female samples. All pelvic organs, including the ureter and rectum were examined. Not all samples contained complete urogenital structures. Mouse IgG was used as a negative control for all the tissues, which were examined by immunohistochemistry.

\section{UGS}

AR immunoreactivity was found in the UGS (Tables 1 and 2 and Figs 2 and 3). In the UGS, the most conspicuous reaction was localized in the mesenchymal component. Reaction was strongest in the dense subepithelial mesenchyme around the UGS and the BUG precusors (Figs 2 and $3 \mathrm{E}$ and $\mathrm{J}$ ) at all gestations. There was no difference in the expression pattern of male and female samples.

The epithelium next to the mesenchyme was examined. The appearance of AR-positive cells was seen in the superficial epithelium and increased progressively with advancing gestation. At 8 weeks the epithelium was negative for AR (Tables 1 and 2 and Fig. 2A). At 9 weeks, the basal layers of epithelium remained negative but some superficial cells stained positive (Table 1 and Fig. 2B). At 10 weeks, whilst the basal epithelium was negative, approximately half of the superficial epithelial cells showed positive staining (Tables 1 and 2, Figs $2 \mathrm{~F}$ and 3E). Samples at 11 and 12 weeks showed negative basal epithelial staining but positive staining of most of the superficial epithelial cells (Tables 1 and 2 and Fig. 2E). Staining was similar in male and female samples (Tables 1 and 2).

\section{Phallus}

The phallus was observed to be prominent from the 8th week (Tables 1 and 2). A difference was observed in the staining pattern of the proximal and distal parts of the phallus. The mesenchyme of the proximal phallus was uniformly and strongly stained up to the 12th week in both males and females (Fig. 3A and B). In the females at 8 weeks of gestation, the distal phallus showed some positive staining (Table 1). Thereafter, the distal portion of the female phallus was negative for AR staining up to 11 weeks, when uniform staining of both the proximal and distal part was observed (Table 1).

No AR staining was found in the male distal phallus at 8 or 9 weeks of gestation (Table 2 and Fig. 3B). A few positive cells were seen in one sample at both 10 and 11 weeks, but most of the other samples were free of staining. At 12 weeks, only one male sample was available; this showed uniform staining of both the proximal and the distal phallus. Overall, the pattern of expression was similar in male and female phallus tissues. 
Table 1 AR in the female UGS, phallus, BUG precursor, PMD and MD, rectum and ectoderm. The denominator represents the number of samples and the numerator represents the number of AR-positive samples. $n$ is the number of samples at each gestation.

\begin{tabular}{|c|c|c|c|c|c|}
\hline & 8 weeks $(n=4)$ & 9 weeks $(n=4)$ & 10 weeks $(n=4)$ & 11 weeks $(n=9)$ & 12 weeks $(n=4)$ \\
\hline UGS mesenchyme & $4 / 4$ & $5 / 5$ & $3 / 3$ & $5 / 5$ & $3 / 3$ \\
\hline UGS basal epithelium & $0 / 4$ & $0 / 5$ & $2 / 3$ & $5 / 5$ & $3 / 3$ \\
\hline UGS superficial epithelium & None of the cells & Few cells only & Half of the cells & Most of the cells & Most of the cells \\
\hline Phallus (proximal) & $2 / 2$ & $2 / 2$ & $4 / 4$ & $6 / 6$ & $3 / 3$ \\
\hline Phallus (distal) & $1 / 2$ & $0 / 2$ & $0 / 4$ & $0 / 6$ & $3 / 3$ \\
\hline Urethral groove (basal cells) & $0 / 3$ & $0 / 4$ & $0 / 4$ & $4 / 5$ & $4 / 4$ \\
\hline Urethral folds & $3 / 3$ & $3 / 3$ & $4 / 4$ & $5 / 5$ & $4 / 4$ \\
\hline Genital swelling & $1 / 2$ & $4 / 4$ & $4 / 4$ & $5 / 5$ & $1 / 1$ \\
\hline Genital tubercle & + & + & + & $4 / 4$ & $3 / 3$ \\
\hline PMD & $0 / 2$ & $0 / 3$ & $0 / 1$ & $0 / 3$ & * \\
\hline MD & $0 / 2$ & $3 / 5$ & $2 / 2$ & $0 / 2$ & * \\
\hline Rectum & $0 / 6$ & $0 / 3$ & $0 / 3$ & $0 / 9$ & $0 / 1$ \\
\hline Ectoderm & $0 / 4$ & $0 / 5$ & $0 / 4$ & $0 / 6$ & $0 / 3$ \\
\hline
\end{tabular}

* No samples were available; + , absent at this gestational stage.

Table 2 AR in the male UGS, phallus, BUG, PMD and MD, rectum and genital skin. The denominator represents the number of samples and the numerator represents the number of AR-positive samples. $n$ is the number of samples.

\begin{tabular}{|c|c|c|c|c|c|}
\hline & 8 weeks $(n=4)$ & 9 weeks $(n=9)$ & 10 weeks $(n=8)$ & 11 weeks $(n=8)$ & 12 weeks $(n=1)$ \\
\hline UGS mesenchyme & $4 / 4$ & $8 / 8$ & $8 / 8$ & $5 / 5$ & $1 / 1$ \\
\hline UGS basal epithelium & $0 / 4$ & $0 / 9$ & $4 / 8$ & $5 / 5$ & $1 / 1$ \\
\hline UGS superficial epithelium & None of the cells & Few cells only & Half of the cells & Most of the cells & Most of the cells \\
\hline Phallus (proximal) & $2 / 2$ & $5 / 5$ & $6 / 6$ & $8 / 8$ & $1 / 1$ \\
\hline Phallus (distal) & $0 / 2$ & $0 / 5$ & $1 / 6$ & $1 / 8$ & $1 / 1$ \\
\hline Urethral groove (basal cells) & $0 / 1$ & $0 / 5$ & $0 / 3$ & $6 / 6$ & $1 / 1$ \\
\hline Urethral folds & $1 / 1$ & $4 / 5$ & $3 / 3$ & $6 / 6$ & $1 / 1$ \\
\hline Genital swelling & $1 / 1$ & $6 / 8$ & $5 / 5$ & $7 / 8$ & $1 / 1$ \\
\hline Genital tubercle & + & + & + & $3 / 3$ & $1 / 1$ \\
\hline PMD & * & $0 / 3$ & $0 / 2$ & $0 / 4$ & * \\
\hline $\mathrm{MD}$ & $0 / 1$ & $5 / 5$ & $2 / 2$ & $1 / 5$ & * \\
\hline Rectum & * & $0 / 6$ & $0 / 3$ & $0 / 8$ & * \\
\hline Ectoderm & $0 / 4$ & $0 / 8$ & $0 / 8$ & $0 / 8$ & $0 / 1$ \\
\hline
\end{tabular}

* No samples were available; + , absent at this gestational stage.

\section{Urethral groove and urethral folds}

The basal epithelium in the urethral groove was free of AR staining from 8 to 10 weeks of gestation in the female (Tables 1 and 2 and Fig. 3A-D); however, some superficial epithelial cells were positive (Fig. 3C and D). At 11 and 12 weeks, the majority of samples showed positive staining (Tables 1 and 2).

The urethral folds, comprising subepithelial mesenchyme, stained strongly from 8 to 12 weeks of gestation in both female and male samples (Tables 1 and 2 and Fig. 3A-D). The overall AR expression was similar for both male and female tissues in the majority of the samples.

\section{Genital swelling}

The subepidermal mesenchyme of the perineum and genital swellings showed heavy AR immunoreactivity which was continuous, with expression in the loose mesenchyme surrounding the genital tract (Tables 1 and 2). In the female at 8 weeks of gestation, one sample was negative but all other samples up to 12 weeks showed uniform staining of the genital swelling (Table 1).
In males, AR expression was observed to be present from 8 to 12 weeks (Table 2). At 9 and 11 weeks, the majority of the samples were positive (Table 2). At 12 weeks, one male sample was available; this showed the same pattern of expression as in females (Tables 1 and 2).

\section{Genital tubercle}

The genital tubercle was prominent at 11 and 12 weeks in both males and females (Tables 1 and 2). At this stage of gestation AR expression was strongly positive (Fig. 3F). AR expression was similar in both the male and female embryos.

\section{PMD and MD}

Figure $2 \mathrm{C}$ and $\mathrm{D}$ shows the fusion zone of $\mathrm{PMD}$ and $\mathrm{MD}$ with the posterior wall of the UGS in females at 10 weeks. The MD lie lateral to the PMD (Fig. 2C and D). In the female PMD, no AR-positive staining was observed from 8 to 11 weeks gestation (Table 1 and Fig. 2C). Whilst in the female MD no positive staining was seen at 8 weeks (Table 1), at 9 weeks three out of five samples 

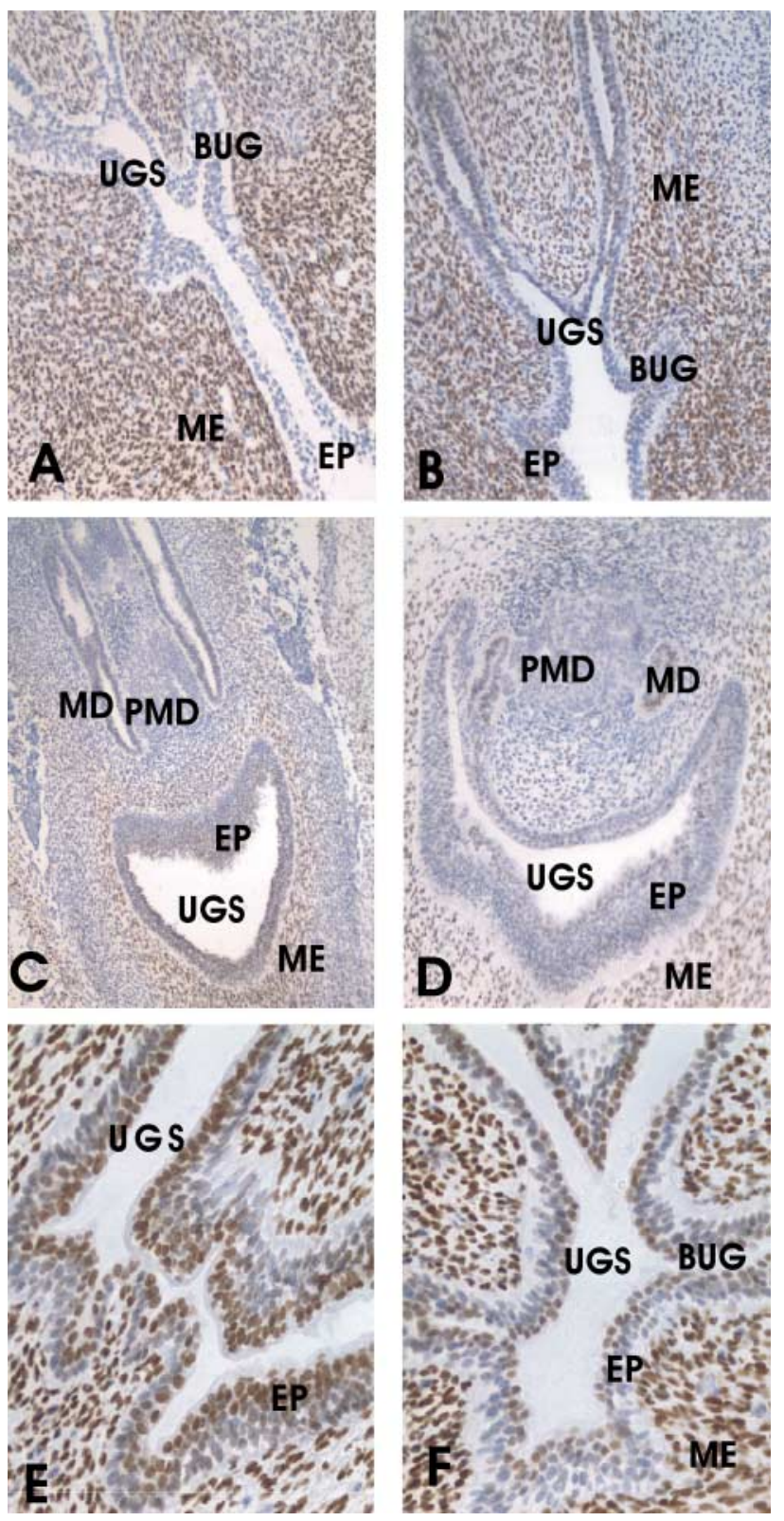

Figure 2 (A and B) Similar staining of AR in (A) 8-week female and (B) 9-week male UGS region with BUG arising from it. The mesenchyme (ME) surrounding the UGS shows strong staining. The epithelium (EP) lining the UGS and BUG lacks any staining in (A) and stains only a few superficial cells in (B) $(\times 200)$. (C and D) Similar pattern of AR staining in (C) 9-week female and (D) 9-week male upper UGS region. These show the UGS and its relationship with the PMD and the MD. The PMD can be seen in the process of joining together, with the MD on its lateral side, just before it enters the posterior wall of the UGS. The ME surrounding the UGS and the ducts is positively stained with AR. The basal layer of the EP lining the UGS is mainly negative; however, positive staining is seen in a few cells in more superficial layers. The PMD lacks AR staining, but the MD show positive staining $(\times 100(C)$ and $\times 200(D))$. (E) 12-week female and $(F)$ 10-week male UGS. The ME shows positive staining. In contrast, the basal EP of the UGS and BUG show negative staining. About half of the superficial UGS epithelial cells are positive in $(F)$ and most of the superficial cells are strongly stained with AR in $(E)(\times 400)$. The AR staining is the brown coloration.
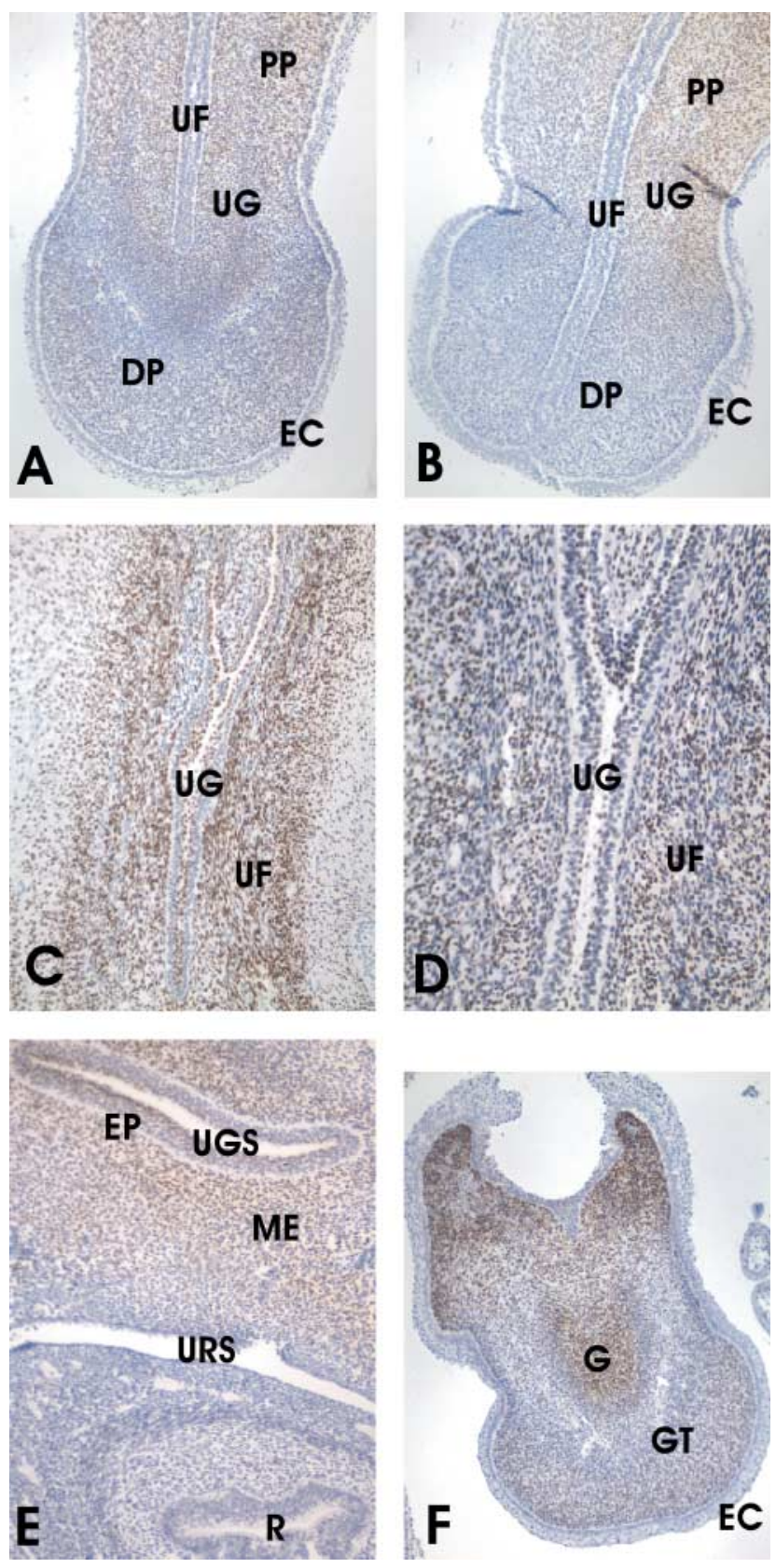

Figure 3 ( $A$ and B) Similar pattern of staining in 9-week (A) female and $(B)$ male phallus, showing more AR staining in the proximal part (PP) than the distal phallus (DP). The urethral folds (UF) shows strong staining but the urethral groove (UG) is negative in most of its part except superficially where one or two cells are seen to be positive with AR $(\times 100)$. ( $C$ and D) Similar staining in $(C)$ a 10week female and (D) a 10-week male fetus. The UG shows negative staining in the basal cells but positive in the superficial cells. The UF mesenchyme was positively stained $(\times 100$ (C) and $\times 100$ (D)). (E) 10-week male with the UGS separated by urorectal septum (URS) from the rectum (R). The R shows no staining, but the UGS is positively stained with AR in the surrounding ME. Its associated EP was negative basally and positive superficially in about half of the cells $(\times 100)$. $(F)$ The genital tubercle (GT) in a 12-week male with the glans $(G)$ showing strong staining at this stage of gestation. The ectoderm $(E C)$ remains negative for $A R(\times 100)$. The AR staining is the brown coloration. 
showed positive AR cells. At 10 weeks, the MD in females stained positive (Table 1), but at 11 weeks staining was absent (Table 1). In the male PMD, all the samples at 9-11 weeks of gestation were negative for AR staining (Table 2 and Fig. 2D).

The MD at 8 weeks was negative for AR in males. At 9 and 10 weeks all the male samples showed strong staining of the MD (Table 2) whilst at 11 weeks only one out of five male samples were positive (Table 2).

\section{BUG precursors}

The BUG precursors are seen arising as epithelial outgrowths from the UGS penetrating the surrounding mesenchyme (Fig. 2A, B and F). These exhibited a similar pattern of staining to the UGS epithelium and mesenchyme (Fig. 2A, B and F).

\section{Rectum}

The rectum and layers of the rectal wall were negative for AR in all female and male samples (Tables 1 and 2) although the surrounding mesenchyme of the UGS was strongly positive.

\section{Ectoderm}

The future epidermal component of the genital skin in the UGS was negative in both male and female samples at 8-12 weeks of gestation (Tables 1 and 2 and Fig. 3F). This was also true for the ectoderm of the phallus (Fig. $3 \mathrm{~A}$ and $\mathrm{B}$ ).

\section{Ureter}

The lower ends of the ureters were seen in some of the samples in both males and females. They were observed to have positive AR staining. The ureter lies considerably lateral in the pelvis to the structures which were the focus of this study and hence they were found in only a few sections.

\section{Discussion}

The $A R$ is a ligand-operated nuclear transcription factor which, after activation, binds to the promoter region of its DNA sequence (Rundlett et al. 1990). Binding of the ligand resulted in a conformational change with disaggregation from heat shock proteins, dimerization of the receptor molecule, transfer to the nucleus and specific binding to nuclear DNA (Drews et al. 2001).

In this study, AR staining was always found in the nuclei of the cells, suggesting that ligand interaction had taken place. This nuclear staining was even seen in female embryos where minimal androgens are present. We suggest that the ligand-independent activation of the AR that has been described in prostate cancer (Ueda et al. 2002) may occur in the embryo. In the embryo, androgen determines the morphogenesis of the genital tract via phase-specific expression of AR primarily in the mesenchyme (Georget et al. 1997). Androgen regulates the functional state of the male sex organs via the AR located in the nuclei of epithelial cells (Georget et al. 1997).

In the present study, we have demonstrated the appearance of AR-positive staining in the mesenchyme of the UGS, followed by the appearance of positive staining in the epithelium. The UGS, after the indifferent stage, gives rise to bladder and posterior urethra in the male, whilst in the female it is responsible for the formation of the bladder, the whole urethra and the vaginal vestibule (Bentvelson et al. 1995). Embryologically, the bladder is formed from both mesodermally derived mesenchyme and endodermally derived epithelial cells (Baskin et al. 1996). In our study, the UGS mesenchyme was positive from 8 to 12 weeks in both males and females. Expression appeared to be temporally regulated in the epithelium lining the UGS. AR was absent from the epithelium at 8 weeks; thereafter staining remained negative in the basal layer but became progressively positive in superficial layers of the epithelium between 9 and 12 weeks of gestation.

The pattern of AR expression first in the mesenchyme followed by appearance in the epithelium provides evidence to suggest that mesenchyme may influence the proliferation of its epithelium. However, further experiments are needed to confirm this interaction. Mesenchymal cells have the ability to invade and migrate through the extracellular matrix to create cell transposition (Hay 1995). Mesenchymal epithelial interactions play critical roles in the development of many organ systems including the gastrointestinal system and the genitourinary organs (Cunha 1976a, Cunha et al. 1980, 1983, Chung et al. 1984, Kedinger et al. 1986, Hall, 1987, Kurzrock et al. 1999). UGS mesenchyme has been previously shown to regulate epithelial proliferation (Chung \& Cunha 1983, Shannon \& Cunha 1983, Sugimura et al. 1986). Mesenchyme-induced epithelial development culminates in the emergence of specific types of epithelial cytodifferentiation and the expression of tissue-specific secretory proteins (Kedinger et al. 1986).

The action of hormones such as oestrogen, progesterone and testosterone appears to be mediated through steroid receptors in the developing genital tract (Kurzrock et al. 1999). Despite the presence of steroid receptors in the epithelium, the action of hormones on the epithelium is mediated by receptors in the mesenchyme of organs, and epithelial mesenchymal cell-cell contact is not obligatory for induction of epithelial differentiation (Cunha \& Chung 1981, Cooke et al. 1998).

Conversely, for both male and female genital tract development, mesenchymal epithelial interactions are reciprocal in that the epithelium may also stimulate the proliferation of mesenchymal cells (Murakami \& Mizuno 1986, Cunha et al. 1992). The competence of an epithelium to respond to inductive stroma is limited by the genotype of the epithelium (Coulombre \& Coulombre 
1971, Dhouailly 1973) and by its age (Cunha 1972, 1976b, 1986).

Animal work has shown that cell-cell interactions between the bladder mesenchyme and epithelium are necessary for the induction of smooth muscle and hence normal bladder development (Baskin et al. 1996). This is also true for the developing prostate epithelial-mesenchymal interaction during their development (Baskin et al. 1996, Hayward et al. 1998).

Many paracrine growth factors are implicated in the development of the genitourinary organs (Nelson et al. 1991, Takahashi et al. 1994) but, to our knowledge, this is the first study in which AR expression has been examined in the UGS of first trimester human embryos. The temporal expression of $A R$, together with the similar expression in male and female embryos, suggests that AR are responsible for growth rather then acting as differentiating factors for the differentiation of sex. A gene programme for epithelial and mesenchymal differentiation may control embryonic development and this, in turn, could be under the control of master regulatory genes (Hay, 1989, 1990).

These mesenchymal cells are the target cells for androgens and play an essential role in morphogenesis caused by androgen (Kratochwil \& Schwartz 1976, Cunha \& Lung 1978, Shannon \& Cunha 1983, Takeda et al. 1984). The binding of androgen to the mesenchymal cells may be responsible for the changes in the phallus, where AR expression was observed predominantly in the proximal part compared with the distal. This may be a developmental phenomenon, where the most proximal cells develop first, followed by the distal: a proximal-distal sequence. This phenomenon has been described in rats, where development of the skeletal tissues in the rat penis proceeds in a proximal-distal sequence (Murakami \& Mizuno 1986). In our study, urethral folds and the genital swellings were positive from 8 to 12 weeks of gestation, but there was minimal staining of the urethral groove epithelium until 11 weeks of gestation.

The genital tubercle was prominent and AR positive at 11 and 12 weeks in both males and females. In rats, the binding of testosterone to the mesenchymal cells in the genital tubercle and prepuce suggests that the mesenchymal cells are essential in causing the morphogenetic changes in the penis, such as canalization of the urethral epithelium and growth of the glands and prepuce. This may be true for human male development, where the Leydig cells of the testis start producing testosterone by 8 weeks (post ovulatory) (10 weeks post LMP) (Sadler 1995). Why the same pattern was seen in females is not known. In previous murine studies, nuclear oestradiol binding in the developing vagina and uterus was limited to the mesenchymal tissue compartment, suggesting that morphogenetic effects of steroid hormones on the epithelium may be mediated by the mesenchyme (Stumpf et al. 1980, Cunha et al. 1982).

In the genital tract, comprising the MD and the joined PMD just before it enters the UGS, AR expression was observed in the mesonephric structures after the end of the indifferent stage (8 weeks of gestational age) when both ductal systems have already been laid down. The $M D$ and the surrounding mesenchyme were AR positive at 9 and 10 weeks, thereafter showing negative staining, but the PMD and its surrounding wall layers were found to be AR negative at all times. At this stage, sex-specific differentiation is already far advanced but the same pattern of AR expression was observed in both sexes. We have shown in our previous work on fetal gonads (submitted) that the upper MD were AR positive from 8 to 11 weeks in both males and females, whilst AR were demonstrated in the epithelium of the PMD in the female and while the associated mesenchyme was free of AR. In males, the opposite effect was seen, i.e. the epithelium of the PMD was found to be negative but the mesenchyme was positive. This suggested that AR in the epithelium could be responsible for the growth of the Fallopian tubes in females, whilst in males the AR in mesenchyme may be responsible for the regression in the upper end of this structure.

In this study, as ARs were absent in both male and female PMD this may suggest that factors other than AR expression may be responsible for PMD regression in the male and further development in the female. MIF, secreted by developing Sertoli cells (Josso et al. 1993, Lee \& Donahoe 1993, Drews et al. 2001), transforms male PMD to mesenchyme and is responsible for the regression of the PMD (Trelstad et al. 1982). This regression begins at 10 weeks of gestation (Taguchi et al. 1984). In the female, the Mullerian system will develop into the female reproductive tract but the PMD has no AR so its differentiation and growth cannot be caused or controlled by androgen. Other growth factors, as yet unknown, may be responsible.

The BUG precursor in the male stained in a similar way to the adjacent UGS. BUG formation involves epithelialmesenchymal interactions, where mesenchymal cells develop AR and appear to be the primary targets of the circulating androgen hormone (Carlson 1999). The significance of $A R$ in female BUG is not clear. It has been suggested that mesenchymal cells act on the associated epithelium through the local paracrine effects of growth factors causing it to differentiate with gland-specific characteristics (Carlson 1999). Human fetal prostate differentiation begins with mesenchymal changes near the urethral epithelium shortly after the beginning of androgen secretion by the fetal testis in the 8th week of development (Kellokumpu-Lehtinen et al. 1979, KellokumpuLehtinen 1980). At the same time, expression of AR coincides with this surge of testosterone from the embryonic testis (Drews et al. 2001).

The rectum and the ectoderm covering the perineum expressed no AR. AR has been shown to be present later in the pelvic muscle, suggesting that it may mediate the effect of androgens on the development of the striated muscle of the pelvic floor and skeletal elements of the pelvic girdle (Drews et al. 2001). Ureter samples were positively stained 
with AR although not all samples contained the ureter. It has been suggested that the expression of the AR in the loose mesenchyme surrounding the UGS, tissues lying between the future bladder and rectum, could be indicative of androgen effects during the ascent of the kidneys and descent of intraperitoneal organs (Drews et al. 2001). This may explain the presence of $A R$ in the ureter.

In conclusion, the present immunohistochemical studies of the human fetal urogenital structures have shown that AR initially appear in the mesenchyme during morphogenesis of the genital structures, followed by the appearance of these receptors in the epithelium, concomitant with its functional differentiation. The exact mechanisms by which the hormone-primed mesenchyme promotes further development of these structures via epithelial stimulation and differentiation are still unclear and further work is needed.

\section{References}

Aumuller G, Holterhus PM, Konrad L, Rahden BV, Hiort O, Murielle E \& Verhoeven G 1998 Immunohistochemistry and in situ hybridisation of the androgen receptor in the developing human prostate. Anatomy and Embryology 197 199-208.

Baskin LS, Hayward SW, Young P \& Cunha GP 1996 Role of mesenchymal-epithelial interactions in normal bladder development. Journal of Urology 156 1820-1827.

Bentvelson FM, Brinkmann AO, Van der Schoot $\mathrm{P}$, Van der Linden JETM, Van der Kwast TH, Boersma WJA, Schröder FH \& Nijman JM 1995 Developmental pattern and regulation by androgens of androgen receptor expression in the urogenital tract of the rat. Molecular and Cellular Endocrinology 113 245-253.

Carlson BM 1999 Urogenital system. In Human Embryology and Developmental Biology, 2nd edn, pp 384-385. St Louis, MO: Mosby, Inc.

Chung LWK \& Cunha GR 1983 Stromal-epithelial interaction. II. Regulation of prostatic growth by embryonic urogenital sinus mesenchyme. Prostate 4 503-511.

Chung LWK, Matsuura J \& Runner MN 1984 Tissue interaction and prostatic growth. I Induction of adult mouse prostatic hyperplasia by fetal urogenital sinus implants. Biology of Reproduction 31 $155-165$.

Cooke PS, Young P \& Cunha GR 1991a Androgen receptor expression in developing male reproductive organs. Endocrinology 128 2867-2873.

Cooke PS, Young P \& Cunha GR 1991b Estrogen receptor expression in developing epidydimis, efferent ductules and other male reproductive organs. Endocrinology 128 2874-2879.

Cooke PS, Buchanan DL, Lubahn DB \& Cunha GR 1998 Mechanism of estrogen action: lessons from the estrogen receptor-alpha knockout mouse. Biology of Reproduction 59 470-475.

Coulombre JL \& Coulombre AJ 1971 Metaplastic induction of scales and feathers in the corneal anterior epithelium of the chick embryo. Developmental Biology 25 464-478.

Cunha GR 1972 Epithelio-mesenchymal interactions in primordial gland structures which become responsive to androgenic stimulation. Anatomical Record 172 179-196.

Cunha GR 1976a Epithelial stromal interactions in development of the urogenital tract. International Review of Cytology 47 137-194.

Cunha GR $1976 b$ Stromal induction and specification of morphogenesis and cytodifferentiation of the epithelia of the mullerian ducts and urogenital sinus during development of the uterus and vagina in mice. Journal of Experimental Zoology 196 361-370.

Cunha GR 1986 Development of the urogenital tract. In Urologic Endocrinology, pp 6-16. Ed. J Rajfer. Philadelphia: Saunders.
Cunha GR \& Lung B 1978 The possible influence of temporal factors in androgenic responsiveness of urogenital tissues recombinants from wild type and androgen insensitive ( $\mathrm{Tfm}$ ) mice. Journal of Experimental Zoology 205 181-194.

Cunha GR \& Chung LWK 1981 Stromal epithelial interactions. I. Induction of prostatic phenotype in urothelium of testicular feminized $(\mathrm{Tfm} / \mathrm{y})$ mice. Journal of Steroid Biochemistry $\mathbf{1 4}$ 1317-1321.

Cunha GR, Reese BA \& Sekkingstad M 1980 Induction of nuclear androgen-binding sites in epithelium of the embryonic urinary bladder by mesenchyme of the urogenital sinus of embryonic mice. Endocrinology 107 1767-1772.

Cunha GR, Shannon JM, Vanderslice KD, Sekkingstad M \& Robboy S) 1982 Autoradiographic analysis of nuclear estrogen binding sites during postnatal development of the genital tract of female mice. Journal of Steroid Biochemistry 17 281-286.

Cunha GR, Fuji H, Neubauer BL, Shannon JM, Sawyer L \& Reese BA 1983 Epithelial-mesenchymal interactions in prostatic development. I. Morphological observations of prostatic induction by urogenital sinus mesenchyme in epithelium of the adult rodent urinary bladder. Journal of Cell Biology 96 1662-1670.

Cunha GR, Battle E, Young P, Brody J, Donjacour A, Hayashi N \& Kinbara H 1992 Role of epithelial-mesenchymal interactions in the differentiation and spatial organization of visceral smooth muscle. Epithelial Cell Biology 1 76-83.

Dhouailly D 1973 Dermo-epidermal interactions between birds and mammals: differentiation of cutaneous appendages. Journal of Embryology and Experimental Morphology 30 587-603.

Drews U, Sulak O \& Oppitz M 2001 Immunohistochemical localisation of androgen receptor during sex-specific morphogenesis in the fetal mouse. Histochemistry and Cell Biology 116 427-439.

Georget V, Terouanne B, Lumbroso S, Nicolas JC \& Sultan C 1997 Trafficking of androgen receptor mutants fused to green fluorescent protein: a new investigation of a partial androgen insensitivity syndrome. Journal of Clinical Endocrinology and Metabolism 83 $3597-3603$.

Hall BK 1987 Tissue interactions in the development and evolution of the vertebrate head. In Development and Evolution of the Neural Crest, pp 215-260. Ed. PFA Maderson. New York: Wiley and Sons.

Hay ED 1989 Theory for epithelial-mesenchymal transformation based on the 'fixed cortex' cell motility model. Cell Motility and the Cytoskeleton 14 455-457.

Hay ED 1990 Epithelial-mesenchymal transitions. Seminars in Developmental Biology 1 347-356.

Hay ED 1995 An overview of epithelio-mesenchymal transformation. Acta Anatomica 154 8-20.

Hayward SW, Haughney PC, Rosen MA, Gruelich KM, Weier HUG, Dahiya R \& Cunha GR 1998 Interactions between adult human prostatic epithelium and rat urogenital sinus mesenchyme in a tissue recombination model. Differentiation 63 131-140.

Jirásek JE 1967 The relationship between the structure of testis and differentiation of the external genitalia and phenotype in man. In Endocrinology of the Testis, vol 16. Ciba Foundation Colloquia on Endocrinology.

Jirásek JE 1971 Genital ducts and external genitalia: development and anomalies. Birth Defects 7 131-139.

Jirásek JE, Raboch J \& Uher J 1968 The relationship between the development of gonads and external genitalia in human fetuses. American Journal of Obstetrics and Gynecology 101 830-833.

Jirásek JE, Sulcovă J, Capková A, Röhling S \& Starka L 1969 Histochemical and biochemical investigations of $3 \beta$-hydroxy$\Delta 5$-steroid dehydrogenase in the chorion, adrenals and gonads of human fetuses. Endocrinology 54 173-183.

Josso N, Lamarre I, Picard JY, Berta P, Davies N, Morichon N, Peschanski M \& Jeny R 1993 Anti-Mullerian hormone in early human development. Early Human Development 33 91-99.

Kedinger M, Simon-Assmann PM, Lacroix B, Marxer A, Hauri HP \& Haffen K 1986 Fetal gut mesenchyme induces differentiation of 
cultured intestinal endodermal and crypt cells. Developmental Biology 113 474-483.

Kellokumpu-Lehtinen P 1980 The histochemical localisation of acid phosphatase in human fetal urethra and prostatic epithelium. Investigative Urology 17 435-440.

Kellokumpu-Lehtinen P 1984 Age determination of early human embryos and fetuses. Annals of Human Biology 11 567-570.

Kellokumpu-Lehtinen P, Santti R \& Pelliniemi LJ 1979 Early cytodifferentiation of human fetal prostate and leydig cells. Anatomical Record 194 429-444.

Kratochwil K \& Schwarz P 1976 Tissue interaction in androgen response of embryonic mammary rudiment of mouse: identification of target tissue for testosterone. PNAS 73 4041-4044.

Kurzrock EA, Baskin LS, Li Y \& Cunha GR 1999 Epithelial-mesenchymal interactions in development of the mouse fetal genital tubercle. Cells Tissues Organs 164 125-130.

Lee MM \& Donahoe PK 1993 Mullerian inhibiting substance: a gonadal hormone with multiple functions. Endocrine Reviews $\mathbf{1 4}$ $152-164$.

Loy CJ \& Yong EL 2001 Sex, infertility and the molecular biology of the androgen receptor. Current Opinion in Obstetrics and Gynecology 13 315-321.

Munsick RA 1984 Human fetal extremity lengths in the interval from 9-21 menstrual weeks of pregnancy. American Journal of Obstetrics and Gynecology 149 883-887.

Murakami R \& Mizuno T 1986 Proximal-distal sequence of development of the skeletal tissues in the penis of rat and the inductive effect of epithelium. Journal of Embryology and Experimental Morphology 92 133-144.

Nelson KG, Takahashi NL, Bossert DK, Walmer JA \& McLachlan JA 1991 Epidermal growth factor replaces estrogen in the stimulation of female genital-tract growth and differentiation. PNAS 88 21-25.

Pellinicmi LJ, Fröjdman K \& Paranko J 1993 Cell biology of testicular development. In Molecular Biology of the Male Reproductive System, pp 21-65. Ed. D Dekretser. San Diego: Academic Press, Inc.

Quigley CA, De Bellis A, Marschke KB, El-Awady MK, Wilson EM \& French FS 1995 Androgen receptor defects: historical, clinical and molecular perspectives. Endocrine Reviews 16 271-321.

Rundlett SE, Wu SP \& Miesfeld RL 1990 Functional characterisations of the androgen receptor confirm that the molecular basis of the androgen action is transcriptional regulation. Molecular Endocrinology 4 708-714.

Sadler TW 1995 In Langmans Medical Embryology, 7th edn. Baltimore, MD: Williams and Wilkins Press.

Sagimura Y, Cunha GR \& Bigsby RM 1986 Androgenic induction of DNA synthesis in prostatic glands induced in the urothelium of testicular feminised (Tfm/y) mice. Prostate 9 217-225.

Shannon JM \& Cunha GR 1983 Autoradiographic localisations of androgen receptors in the developing mouse prostate. Prostate $\mathbf{4}$ 367-373.

Sajiad Y, Quenby S, Nickson P, Lewis-Jones DI \& Vince G 2004 Expression of androgen receptors in upper human fetal reproductive tract. Human Reproduction (In Press).

Shapiro E, Huang HY \& Wu XR 2000 Uroplakin and androgen receptor expression in the human fetal genital tract: insights into the development of the vagina. Journal of Urology 164 1048-1051.

Siiteri PK \& Wilson JD 1974 Testosterone formation and metabolism during male sexual differentiation in the human embryo. Journal of Clinical Endocrinology and Metabolism 38 113-125.
Streeter GL 1920 Weight, sitting height, head size, foot length and menstrual age of human embryo. Carnegie Institute Contribution. Embryo 11 144-169.

Stumpf WE \& Sar M 1976 Autoradiographic localisation of estrogen, androgen, progestin and glucocorticosteroid in 'target tissue' and 'non target tissue'. In Receptors and Mechanism of Action of Steroid Hormones, pp 41-84. Ed. JR Pasquallini. New York: Marcel Dekker.

Stumpf WE, Narbaitz R \& Sar M 1980 Estrogen receptors in the fetal mouse. Journal of Steroid Biochemistry 12 55-64.

Sugimura Y, Cunha GR \& Donjacour AA 1986 Prostatic glandular architecture: whole-mount analysis of morphogenesis and androgen dependency. In Benign Prostatic Hyperplasia, pp 55-72. Eds $\mathrm{CH}$ Rodgers, DS Coffey, GR Cunha, JT Grayhack, F Hinman \& R Horton. Washington DC: United States Government Printing Office.

Taguchi O, Cunha GR, Lawrence WD \& Robboy SJ 1984 Timing and irreversibility of mullerian duct inhibition in the embryonic reproductive tract of the human male. Developmental Biology 106 394.

Takahashi TB, Eitzman NL, Bossert D, Walmer K, Sparrow KC, Flanders J, McLachlan K \& Nelson G 1994 Transforming growth factors beta 1 , beta 2 and beta 3 messenger RNA and protein expression in mouse uterus and vagina during estrogen-induced growth: a comparison to other estrogen regulated genes. Cell Growth and Differentiation 5 919-935.

Takeda H, Mizuno T \& Lasnitzki I 1984 Autoradiographic studies of androgen binding sites in the rat urogenital sinus and postnatal prostate. Journal of Endocrinology 104 87-92.

Takeda H, Chodak G, Mutchnik S, Nakamoto T \& Chang C 1990 Immunohistochemical localisation of androgen receptors with mono and polyclonal antibodies to androgen receptor. Journal of Endocrinology 126 17-25.

Trelstad RL, Hayashi K \& Donahoe PK 1982 The epithelial mesenchymal interface of the male rat mullerian duct; loss of basement membrane integrity and ductal regression. Developmental Biology 92 27-40.

Ueda T, Mawji NR, Bruchovsky N \& Sadar MDJ 2002 Ligand-independent activation of the androgen receptor by interleukin- 6 and the role of steroid receptor coactivator-1 in prostate cancer cells. Journal of Biological Chemistry 277 38087-38094.

Wasner G, Hennermann I \& Kratochwil K 1983 Ontogeny of mesenchymal androgen receptors in embryonic mouse mammary gland. Endocrinology 113 1771-1780.

Wilson JD, George FW \& Griffin JE 1981 The hormonal control of sexual development. Science 211 1278-1284.

Wilson JD, Griffin JE \& Russell DW 1993 Steroid 5-alpha reductase 2 deficiency. Endocrine Reviews 14 577-593.

Winters JSD, Faiman C \& Reyes F 1981 Sexual endocrinology of fetal and perinatal life. In Mechanisms of Sex Differentiation in Animals and Man, pp 205-227. Eds CR Austin \& RG Edwards. New York: Academic Press.

Received 8 March 2004

First decision 27 April 2004

Accepted 26 May 2004 